\title{
Seismic Vulnerability Assessment of a Historical Church: Limit Analysis and Nonlinear Finite Element Analysis
}

\author{
G. Castellazzi, C. Gentilini, and L. Nobile \\ Department of Civil, Chemical, Environmental, and Materials Engineering, University of Bologna, v.le Risorgimento 2, \\ 40136 Bologna, Italy
}

Correspondence should be addressed to G. Castellazzi; giovanni.castellazzi@unibo.it

Received 6 May 2013; Accepted 25 June 2013

Academic Editor: John Mander

Copyright (C) 2013 G. Castellazzi et al. This is an open access article distributed under the Creative Commons Attribution License, which permits unrestricted use, distribution, and reproduction in any medium, provided the original work is properly cited.

The seismic vulnerability of a historical Basilica church located in Italy is studied by means of limit analysis and nonlinear finite element (FE) analysis. Attention is posed to the failure mechanisms involving the façade of the church and its interaction with the lateral walls. In particular, the limit analysis and the nonlinear FE analysis provide an estimate of the load collapse multiplier of the failure mechanisms. Results obtained from both approaches are in agreement and can support the selection of possible retrofitting measures to decrease the vulnerability of the church under seismic loads.

\section{Introduction}

Recent Italian seismic events, such as the Emilia (2012) and the L'Aquila earthquakes (2009), have demonstrated how churches are susceptible to damage when subjected to earthquake motions [1-3]. In fact, designed to withstand vertical loads, churches in general present slender walls, lack of horizontal structures, weak or nonexistent connections among structural elements, absence of effective tie-rods to absorb arch thrusts [4], and irregular stone texture. These aspects, added to poor material performance especially in tensile stress mode [5], are among the reasons for the structural collapses of historical monumental buildings when subjected to seismic forces.

Cases of damaged or collapsed churches after earthquake events (sometimes also immediately after their renovations) are numerous. It is worthwhile to remember the collapse of St. Possidonio church (Italy) in 2012, the partial collapse of the church of Santiago in Lorca (Spain) in 2011, the collapse of the Catholic Cathedral of Port au Prince in Haiti in 2010 (right after its total restoration), and the partial collapse of the main church in St. Pietro di Coppito (Italy) in 2009, after consistent work of conservation.

In the literature, the approaches employed to analyze the seismic behaviour of masonry structures can be summarized as follows: micromodeling approaches (see e.g., [6,
7]), macromodeling approaches (see e.g., [8]), multiscale approaches (see e.g., [9]), and full-scale approaches (see e.g., [10-14]).

Among these methods, the most suitable to determine the seismic vulnerability of masonry buildings are the latters that correspond to limit analysis and nonlinear FE analysis [15, 16]. Both approaches aim at providing the value of the load that activates the failure mechanisms of the macroelements in which the church can be subdivided. In fact, the behavior at collapse of a masonry church under a seismic event is rarely global since several out-of-plane collapses of macroelements may occur. The experience suggests to consider a limited number of possible failure mechanisms involving the main elements of the church such as the façade, the apse, the naves, the triumphal arch, and the navy walls.

Within this context, the present study presents a nonlinear FE analysis coupled with a limit analysis applied to Madre Santa Maria del Borgo, an Italian church located in San Nicandro Garganico. In particular, the collapse mechanisms involving the façade are analyzed in detail, since reputed potentially critical after a survey. Three mechanisms are identified: an out-of-plane mechanism of the façade, a mechanism involving the façade and the peripheral lateral walls, and a mechanism considering the interaction between the façade, the peripheral lateral walls, and the navy walls. 
The seismic vulnerability of the church has been analysed by means of the following: (i) a preliminary linear dynamic analysis of the whole structure performed to check if a global dynamic behavior of the structure exists and the corresponding global structural interaction among the single elementary parts; (ii) nonlinear FE analyses of the main structural macroelements interacting with the façade performed to identify the collapse loads. Results are integrated with those provided by a limit analysis of each mechanism.

The comparison of the results obtained from the above studies shows a good agreement and provides an estimate of the seismic vulnerability of the church, in particular of the main façade.

The main relevant contribution of the present study is the application of the limit analysis to a masonry church and the validation by a nonlinear analysis of a model prepared according the FEM. As a consequence, the present approach can be readily extended to analyze the seismic vulnerability of other similar churches. Thus, the results of the analyses can be useful to design appropriate retrofitting and restoration measures.

The paper is organized as follows. In Section 1, the church structure is described, highlighting the conservation state through an analysis of the existing cracking pattern. Section 2 presents a first investigation through a linear dynamic analysis of the whole structure. In Section 3, a detailed study of the main mechanisms involving the church façade is presented using a nonlinear FE analysis coupled with a limit analysis. Some conclusive remarks end the paper.

\section{Description of the Church Structure}

Madre Santa Maria del Borgo is the main church of San Nicandro Garganico (Italy); see Figure 1. The construction began between 1573 and 1580 and was completed around 1693, when lateral small buildings and chapels were added to the original project.

The church measures $30 \mathrm{~m}$ and $25 \mathrm{~m}$ of length and width, respectively. The lateral walls, near the façade, are $11 \mathrm{~m}$ high, while the façade height is $14 \mathrm{~m}$.

In general, monumental buildings, such as churches, are characterized by a massive thickness of the walls with few and comparatively small openings. In this case, the wall thickness varies approximately between $0.8 \mathrm{~m}$ along the main nave and $1.1 \mathrm{~m}$ at the apse; see Figure 2(a). These walls are made by double shell tuff stone with different schemes: opus incertum, opus mixtum, and opus quadratum, filled with rubble of the same material; see Figure 3.

The three naves are subdivided by two lines of five columns each. The columns have squared cross-section made by regular bricks of tuff stone. The roof of the church is made by timber except for the roof of the chapel Immaculate, C3, which is realized by masonry (Figure 2(a)). The chapel $\mathrm{C} 4$ is the only one that has a ribbed-slab concrete floor, underneath the roof structure. The main façade is made by regular prismatic stone blocks.

It is interesting to note that the church has been built on an artificial horizontal basement higher than the other buildings around the church; see Figures 2(b) and 2(c). The crypt is located between the internal pavement level and the actual external ground level.

2.1. Conservation Status of the Church: Cracking Pattern. The church presents a diversified cracking pattern characterized by horizontal and vertical damages (Figure 4). In particular, the area near the crypt shows a severe damage/cracking pattern; see Figures 4(b) and 4(c). Possible causes of this situation can be listed as follows: (i) a localized subsiding of the walls located over the crypt due to a settlement of the foundation walls, or (ii) a seismic interaction of the façade and the nave walls associated with an out-of-plane mechanism of the façade. In fact, the church was built on a seismic area and several earthquake events were recorded in this area from the III level to the IX level of the MCS intensity scale.

\section{Linear Dynamic Analysis}

A linear dynamic analysis has been carried out on a 3D finite element model of the church using ABAQUS [17-19]. The 3D FE model has been realized using shell elements to model the midplane masonry walls and using truss elements to model the timber roof structures of the nave and aisles. Shell elements are also employed to model the main vault of the nave, the vault of the apse, the vaults of the $\mathrm{C} 1$ and $\mathrm{C} 2$ chapels, and the vault roof structure of the C3 chapel; see Figure 5. The model consists of 49781 shell elements and 30 truss elements for a total of 49674 nodes.

The analysis aims at finding the dynamic behavior of the church as-built. For this reason, a perfect matching of the walls without any assumed cracking pattern or reduction in wall stiffness is considered.

Boundary conditions have been applied according to the characteristics of the terrain and church pavement. In particular, nodes located at the ground level, see Figure 2(b), have been clamped, whereas only the horizontal displacement has been restrained for the nodes located at the pavement level. To the authors' knowledge, no experimental investigations have been conducted to assess the mechanical properties of the church constituent materials. As a consequence, in this study, the masonry constitutive parameters are derived from the literature [20] for similar materials: Young's modulus $E=$ $1000 \mathrm{MPa}$, Poisson's ratio $\nu=0.07$, and mass density $\rho=$ $2000 \mathrm{~kg} / \mathrm{m}^{3}$.

Results of the analysis are collected in Table 1, where the frequencies of the main mode shapes, characterized by a mass participation factor greater than 3\% in the longitudinal or in the transversal direction, are listed. These results show mainly local modes and just one global mode, no. 7, that corresponds to a frequency equal to $5.334 \mathrm{~Hz}$. Mass participation sum of the first 30 eigen-modes results is equal to $55.5 \%$ and $55.2 \%$ of the total mass in the transversal and longitudinal directions, respectively. It should be noted that this proportion accounts also for the belfry mass. Belfry mode shapes are characterized by lower frequencies if compared with those related to the church structure. As a consequence, the mass participation is not improved significantly if belfry mass is removed from the previous sums. In fact, the sum of the mass participation of the first 30 eigen-modes is equal to $63.5 \%$ and $64.9 \%$ of 


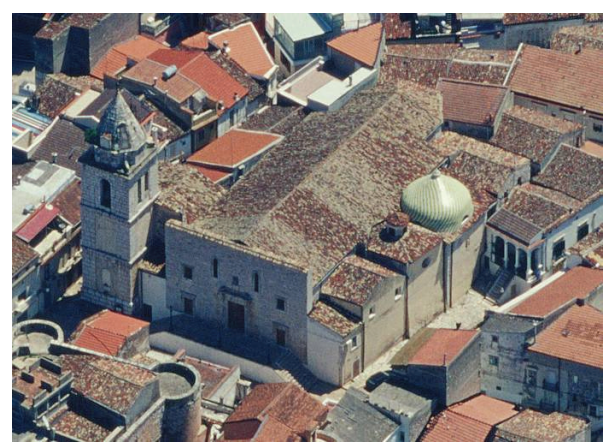

(a)

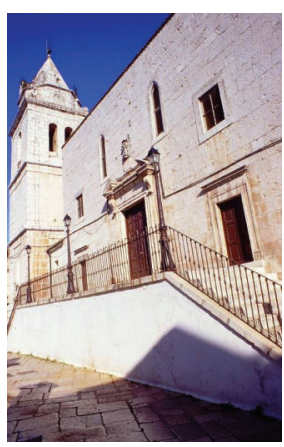

(b)

Figure 1: (a) Photograph of Madre Santa Maria del Borgo church, San Nicandro, Italy, and (b) façade of the church.

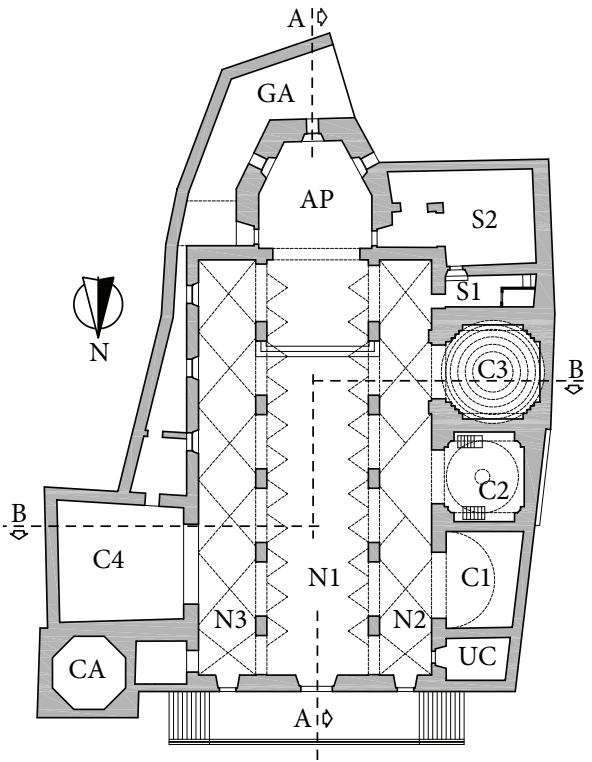

(a)

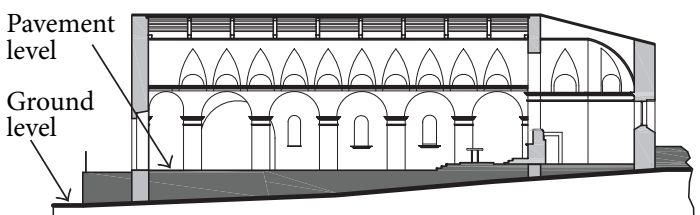

(b)

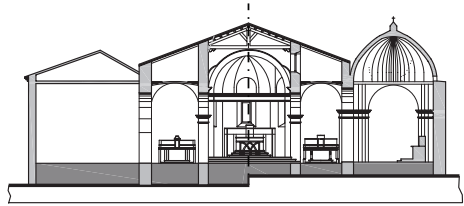

(c)

FIgUre 2: Madre Santa Maria del Borgo church, San Nicandro, Italy: (a) plan layout, (b) longitudinal section A-A, and (c) transversal section B-B.

the total mass in the transversal and longitudinal directions, respectively.

This is a common result for monumental religious buildings, where the particular geometry does not allow to reach high mass participation factors even for relatively simple structures; see, for instance, [11, 21].

Figures 6 and 7 show the transversal and longitudinal sections of the selected eigen-modes, respectively. It can be seen that modes are characterized mainly by local transversal behavior: excitation of the main vault or transversal excitation of lateral and nave walls. It is interesting to note that the longitudinal mode shape, no. 7, see Figure 6(d), involves the façade and the nave walls. Detailed view of the longitudinal section of this mode shape is reported in Figure 8. In the following, this mode is employed to suggest the failure mechanism of the façade macroelement for the nonlinear FE analysis.

\section{Limit Analysis and Nonlinear FE Analysis}

In this section, attention is focused on the study of the seismic vulnerability of the façade of the church conducted by 


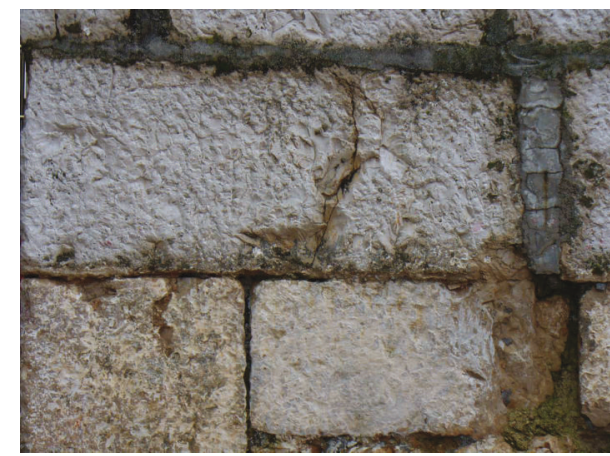

(a) Regular stone masonry: opus quadratum

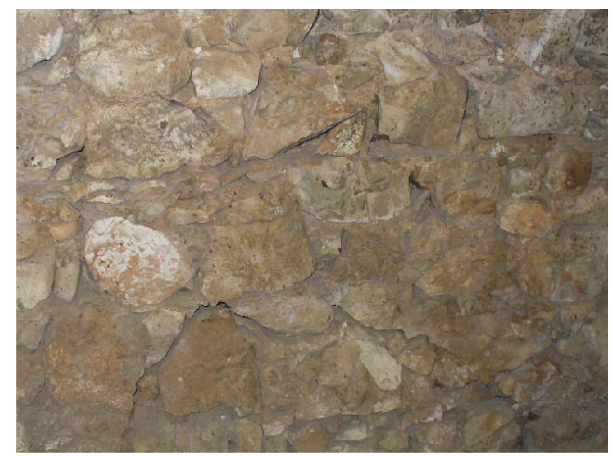

(b) Irregular stone masonry: opus incertum

Figure 3: Madre Santa Maria del Borgo church, San Nicandro, Italy: church walls.

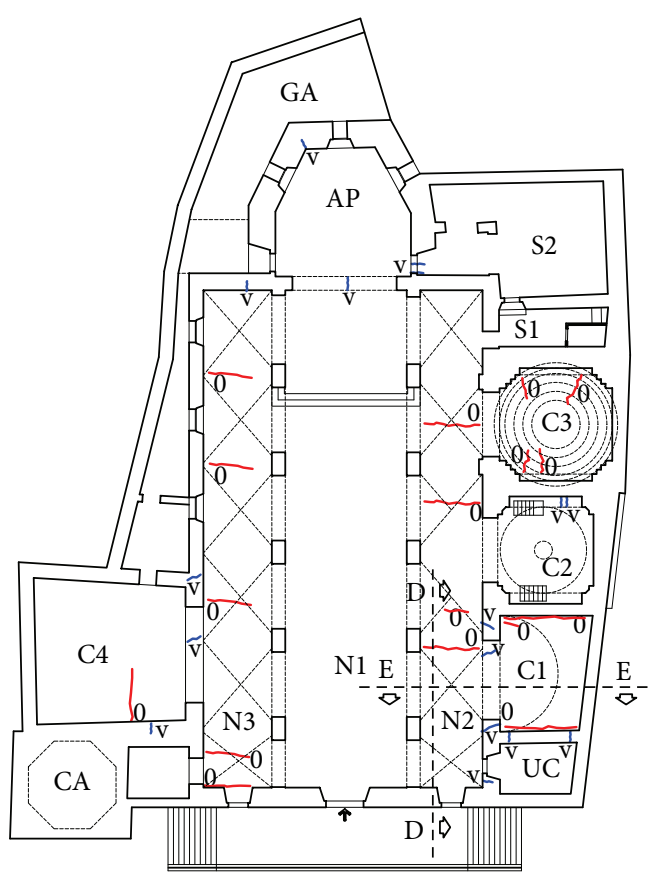

(a)

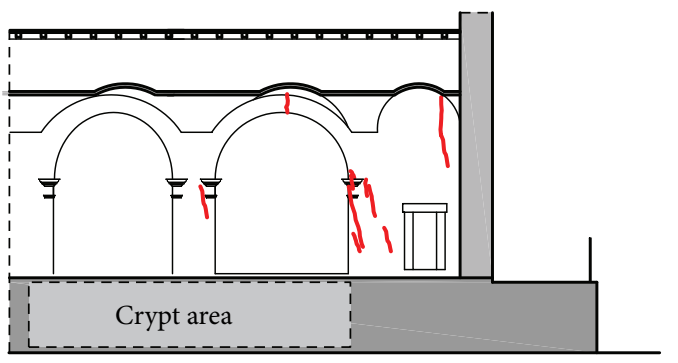

(b)

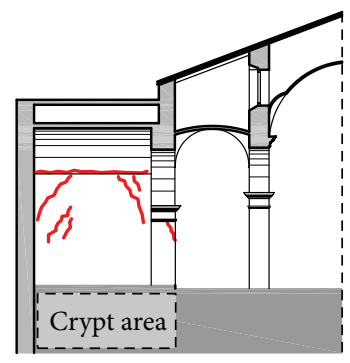

(c)

Figure 4: Madre Santa Maria del Borgo church, San Nicandro, Italy: (a) cracking pattern of the peripheral lateral walls in the area near the façade, (b) longitudinal section D-D, and (c) transversal section E-E.

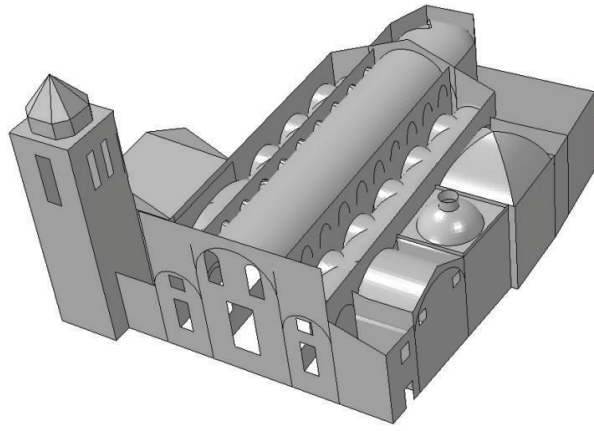

(a)

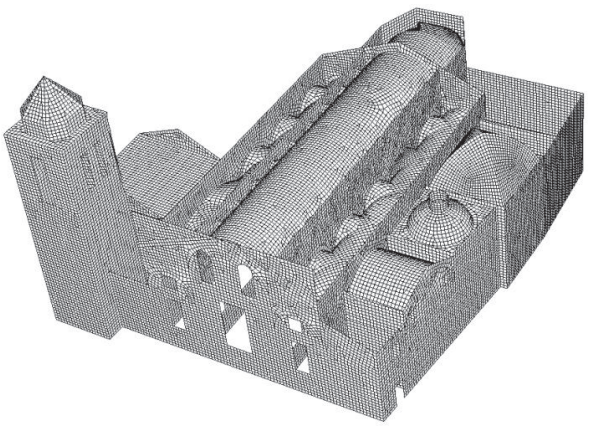

(b)

FiguRE 5: Linear dynamic analysis: 3D FE model of the church (a) geometry of the masonry mid-plane and (b) mesh of the 3D shell elements model. Roof structure is hidden to view. 
TABLE 1: Linear dynamic analysis: frequencies of the main mode shapes of the St. Maria del Borgo Church (bell tower modes are not reported in the present table).

\begin{tabular}{|c|c|c|c|c|}
\hline \multirow{2}{*}{ Mode no. } & \multirow{2}{*}{$\begin{array}{l}\text { Frequency } \\
\qquad(\mathrm{Hz})\end{array}$} & \multicolumn{2}{|c|}{ Mass participation (\%) } & \multirow{2}{*}{ Mode description } \\
\hline & & Transversal & Longitudinal & \\
\hline 4 & 3.656 & 6.79 & 0.16 & $\begin{array}{l}\text { Transversal bending of nave walls, vault support in } \\
\text { phase }\end{array}$ \\
\hline 5 & 4.111 & 14.32 & 0.02 & $\begin{array}{l}\text { Transversal bending of nave walls, vaults support in } \\
\text { phase opposition }\end{array}$ \\
\hline 6 & 5.121 & 0.78 & 4.90 & $\begin{array}{l}\text { Transversal bending of nave walls, vaults support in } \\
\text { phase opposition, small longitudinal bending of the } \\
\text { façade }\end{array}$ \\
\hline 7 & 5.334 & 0.10 & 31.04 & Longitudinal bending of the façade and apse area \\
\hline 10 & 6.182 & 3.71 & 0.01 & $\begin{array}{l}\text { Transversal bending of nave and peripheral lateral } \\
\text { walls, dome predominant }\end{array}$ \\
\hline 12 & 6.328 & 8.88 & 0.02 & Transversal bending of lateral chapel walls \\
\hline 14 & 7.182 & 4.45 & 0.03 & $\begin{array}{l}\text { Transversal bending of nave and peripheral lateral } \\
\text { walls, in-plane bending of façade and triumphal arc }\end{array}$ \\
\hline 20 & 8.189 & 3.33 & 0.38 & $\begin{array}{l}\text { Transversal bending of nave, peripheral lateral walls, } \\
\text { apse and bell tower }\end{array}$ \\
\hline 22 & 8.546 & 0.01 & 3.91 & $\begin{array}{l}\text { Longitudinal bending of façade upper parts, small } \\
\text { torsional behavior }\end{array}$ \\
\hline 27 & 9.270 & 0.12 & 5.19 & $\begin{array}{l}\text { Longitudinal bending of the façade, dome and } \\
\text { peripheral lateral walls in phase opposition }\end{array}$ \\
\hline
\end{tabular}

means of limit analysis and of nonlinear FE analysis. For this purpose, three mechanisms are analyzed: (i) the out-of-plane failure mechanism of the façade considering no interaction with the lateral walls (Figure 9(a)); (ii) the failure mechanism due to the interaction between the façade and the peripheral lateral walls (Figure 9(b)); (iii) the failure mechanism due to the interaction between the façade, the peripheral lateral walls, and the nave walls (Figure 9(c)).

The church has been subdivided into five main macroelements that are involved in the three mechanisms: the façade, the lateral nave wall (wall between $\mathrm{C} 4$ and N3), the lateral nave wall (wall between $\mathrm{N} 2$ and C1-C2-C3-S2), the nave wall (wall between N3 and N1), and the nave wall (wall between N1 and N2); see Table 2.

The analysis of the failure mechanisms is based on the calculation of the parameter which corresponds to the activation of the mechanism, the so called collapse load multiplier. The approaches employed to determine the collapse load multiplier are described in the following.

Limit Analysis. The limit analysis represents a simple and effective tool for deriving an estimate of the ultimate strength capacity of masonry structures [15, 22, 23]. This approach considers no tensile strength and infinite compression strength for the masonry with absence of sliding at failure. In particular, these hypotheses lead to the definition of the term "mechanism": the structure undergoes failure through the formation of cylindrical hinges (corresponding to disconnections and localized cracking) that subdivide the structure into macroelements subjected to inelastic deformations.
With reference to a generic mechanism, see Figure 10, the collapse load multiplier $\alpha_{0}$ can be evaluated by means of the principle of the virtual works:

$$
\begin{gathered}
\alpha_{0}\left(\sum_{i=1}^{n} P_{i} \delta_{x, i}+\sum_{j=n+1}^{n+m} P_{j} \delta_{x, j}\right) \\
-\sum_{i=1}^{n} P_{i} \delta_{y, i}-\sum_{h=1}^{k} F_{h} \delta_{h}=L_{f i},
\end{gathered}
$$

where $P_{i}$ is the self-weight of each macroelement part ( $n$ entries) composing the kinematic mechanism; $P_{j}$ is the weight transmitted to the macroelement by adjacent structures ( $m$ entries); $F_{h}$ is the generic external force applied to a macroelement part ( $k$ entries); $\delta_{x, i}$ and $\delta_{x, j}$ are the horizontal virtual displacements of each macroelement centroid; $\delta_{y, i}$ and $\delta_{h}$ are the vertical virtual displacements of each point of application of $P_{j}$ and $F_{h}$, respectively, while $L_{f i}$ represents the work done by internal forces.

The true collapse multiplier can be found in the class of all the collapse multipliers that are obtained by varying the position of each hinge. Once the collapse multiplier $\alpha_{0}$ has been computed for the considered mechanism, the seismic acceleration of the activation of the mechanism $\alpha_{0}^{*}$ is defined as [24]

$$
\alpha_{0}^{*}=\frac{\alpha_{0} \sum_{i=1}^{n+m} P_{i}}{M^{*}},
$$




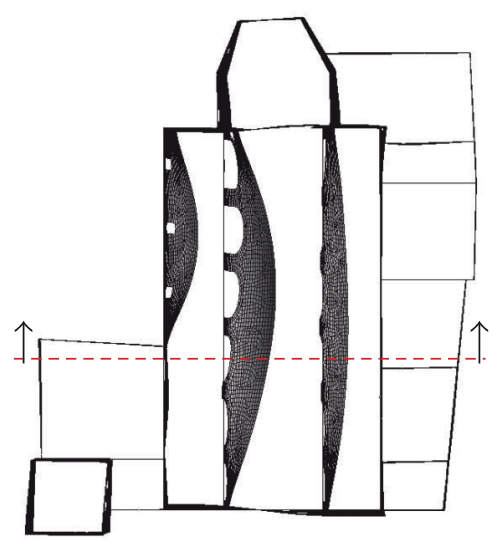

(a) no. 4: freq. $=3.656 \mathrm{~Hz}$

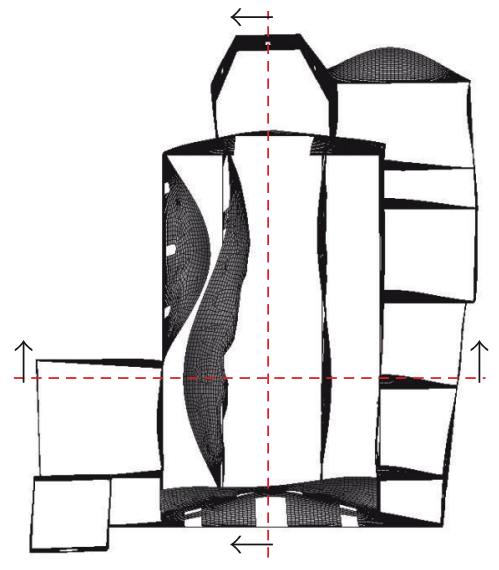

(d) no. 7: freq. $=5.334 \mathrm{~Hz}$

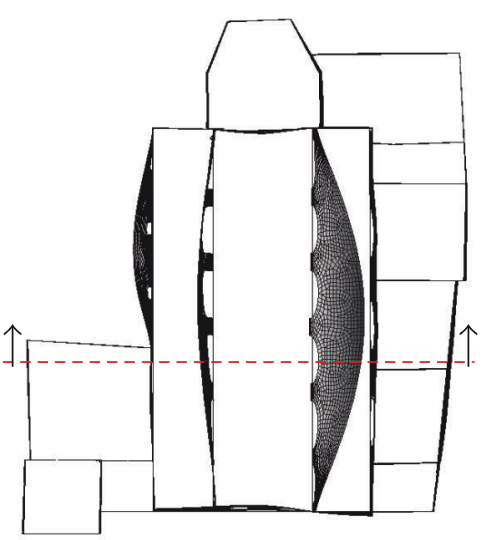

(b) no. 5 : freq. $=4.111 \mathrm{~Hz}$

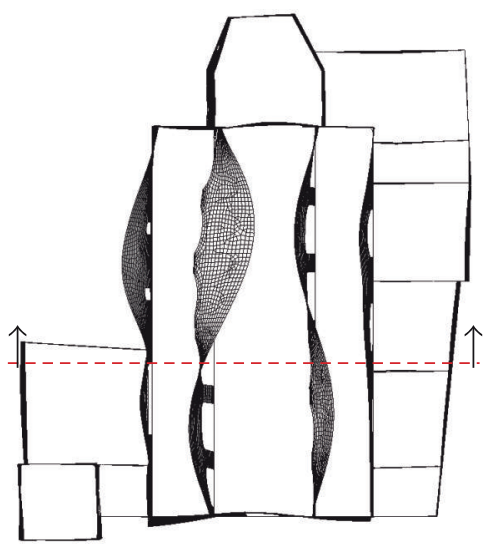

(e) no. 10: freq. $=6.182 \mathrm{~Hz}$

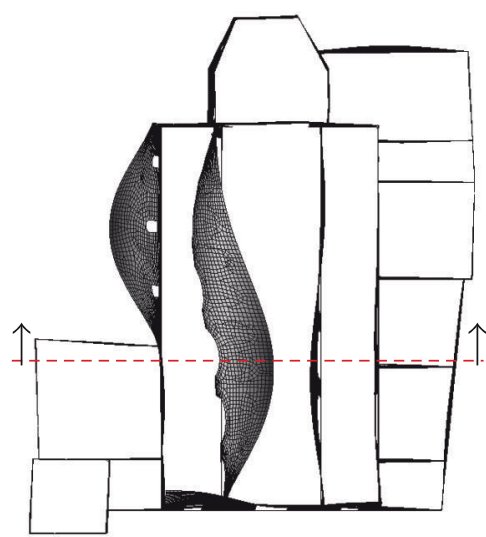

(c) no. 6: freq. $=5.121 \mathrm{~Hz}$

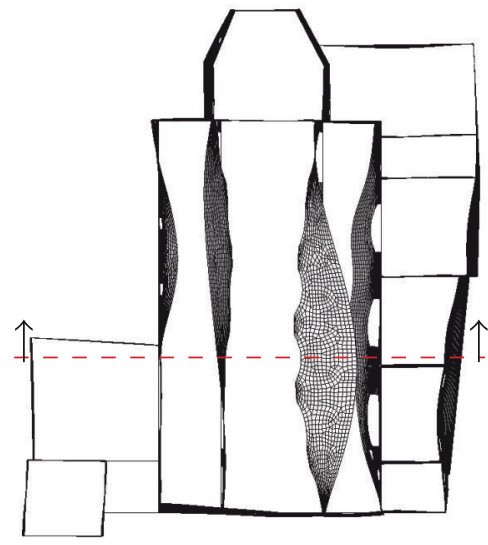

(f) no. 12: freq. $=6.328 \mathrm{~Hz}$

FIGURE 6: Linear dynamic analysis: horizontal section of the horizontal section of the main six eigen-modes. Vaults and roof structures are hidden to view.

where $M^{*}$ is the effective mass that reads as

$$
M^{*}=\frac{\left(\sum_{i=1}^{n+m} P_{i} \delta_{x, i}\right)^{2}}{g \sum_{i=1}^{n+m} P_{i} \delta_{x, i}^{2}}
$$

where $n+m$ is the number of applied forces $P_{i}$ that cause horizontal displacements $\delta_{x, i}$ and $g$ is the gravitational acceleration.

The investigated mechanism is verified comparing the spectral acceleration $\alpha_{0}^{*}$ with the seismic demand $\alpha_{\text {SLU }}^{*}$, [25], that is,

$$
\alpha_{0}^{*} \geq \alpha_{\mathrm{SLU}}^{*}=\frac{a_{g} S}{q}\left(1+1.5 \frac{z}{H}\right),
$$

where $S$ is a factor depending on the ground type. In this case, $S$ is assumed to be equal to 1.0 because it refers to lithoid soil formations or homogeneous very rigid soil, including alterations in superficial layers of maximum thickness of $5 \mathrm{~m}$ (type $A$ in [25]). $a_{g} S$ represents the spectral acceleration for the elastic design (period $T=0$ ), being $a_{g}$ the peak ground acceleration (PGA) for the specific location. In this case, $a_{g}$ equal to $0.25 \mathrm{~g}$ is considered. $z$ is the height of the centroid of masses activated by the mechanism and $H$ is the total height; see Figure 10.

According to the Italian standards [24], for masonry structures $q$ is equal to 2 . For the church under consideration made of unreinforced stone masonry, a more severe choice of $q$ is desirable. As a consequence, the parameter $q$ is set to equal to 1.5 .

Nonlinear FE Analysis. Finite element analyses are carried out using the commercial computer program ABAQUS. The tool allows to solve a variety of highly nonlinear structural problems for concrete [26], metallic [27], and masonry [28] structures. In order to model the nonlinear behavior of the masonry material, the smeared crack model is adopted. The smeared crack (or concrete model) is a multicrack model based on a yield surface with isotropic hardening and associated flow when the state of stress is predominantly compressive and it uses damaged elasticity to account for the cracking. The cracking phenomenon is modeled by means of the so-called crack detection surface: a simple coulomb line written in terms of the first and second stress invariants. 


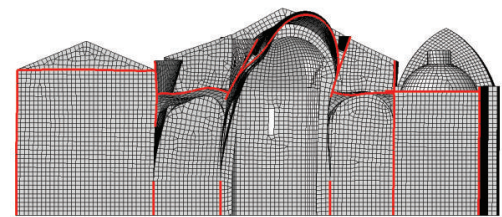

(a) no. 4 : freq. $=3.656 \mathrm{~Hz}$

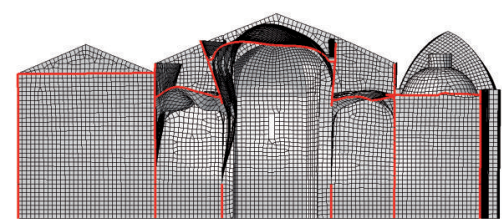

(d) no. 7: freq. $=5.334 \mathrm{~Hz}$

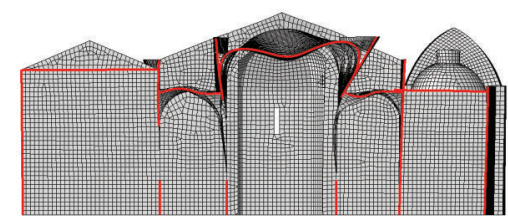

(b) no. 5 : freq. $=4.111 \mathrm{~Hz}$

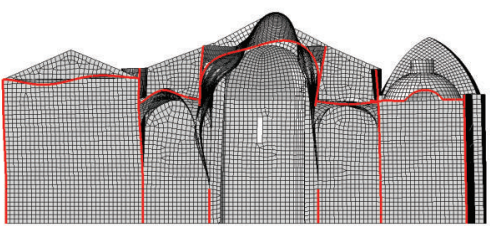

(e) no. 10 : freq. $=6.182 \mathrm{~Hz}$

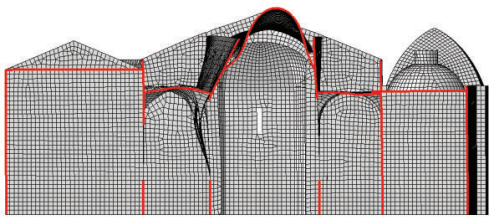

(c) no. 6: freq. $=5.121 \mathrm{~Hz}$

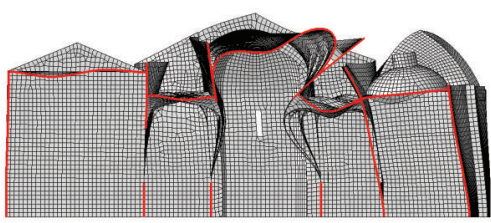

(f) no. 12 : freq. $=6.328 \mathrm{~Hz}$

FIGURE 7: Linear dynamic analysis: transversal section of the of the main six eigen-modes.

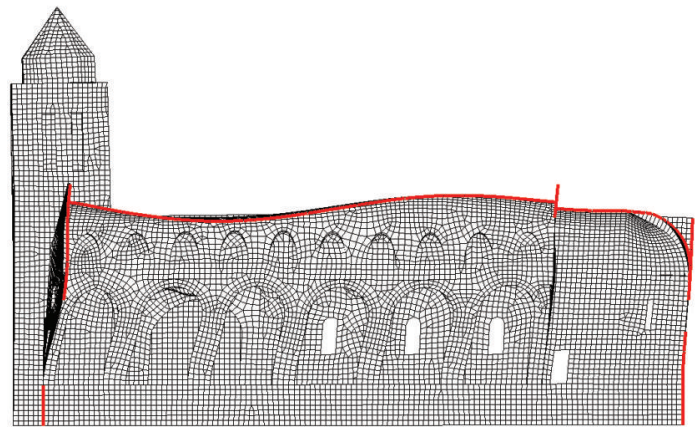

FIGURE 8: Linear dynamic analysis: longitudinal section of the eigen-mode, no. 7.

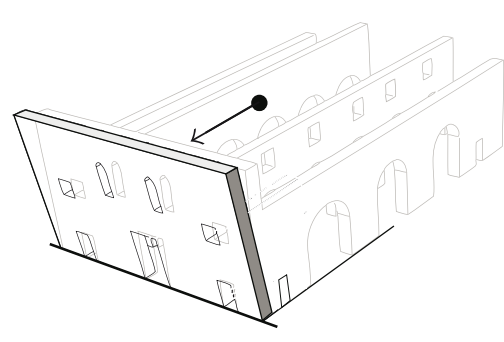

(a)

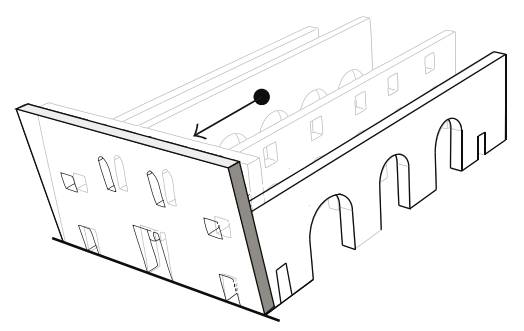

(b)

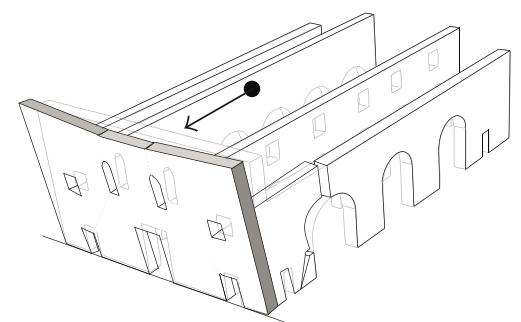

(c)

Figure 9: Out-of-plane mechanisms of the façade macroelement. (a) Mechanism 1: out-of-plane mechanism of the façade; (b) mechanism 2: interaction between the façade and the peripheral lateral walls; (c) mechanism 3: interaction between the façade, the peripheral lateral walls, and the nave walls. Roof structure and surrounding chapels are here hidden to view. Light gray parts in the picture are not part of the mechanism.

Designed to predict the nonlinear behavior of concrete, the model has some limitations when applied to masonry. The model is not capable of predicting cyclic response and the use of associated flow usually leads to an overprediction of the volume strain. Nevertheless, the ABAQUS smeared crack model has proven to reasonably predict the masonry behavior in monotonic loading, as long as proper material definition is provided [29].

The model requires the definition of few parameters. In this study, the stress-strain curve in compression is taken according to experimental campaign done on similar materials [20]. Moreover, the shape of the failure surface and the postcracking tensile behavior are required to calibrate correctly the model. Setting the failure ratios option (FR), compression strength $c_{s}$, tension strength $t_{s}$, and the tension stiffening option (TS), the failure surface and the postcrack behaviour are defined. The selected values result in $\mathrm{FR}=(1.12$, $0.1,1.33,0.2), c_{s}=3.3 \mathrm{MPa}$, and $t_{s}=0.33 \mathrm{MPa}$. Threedimensional elements, such as hexahedral and tetrahedral elements, are employed to model the macroelements. This 


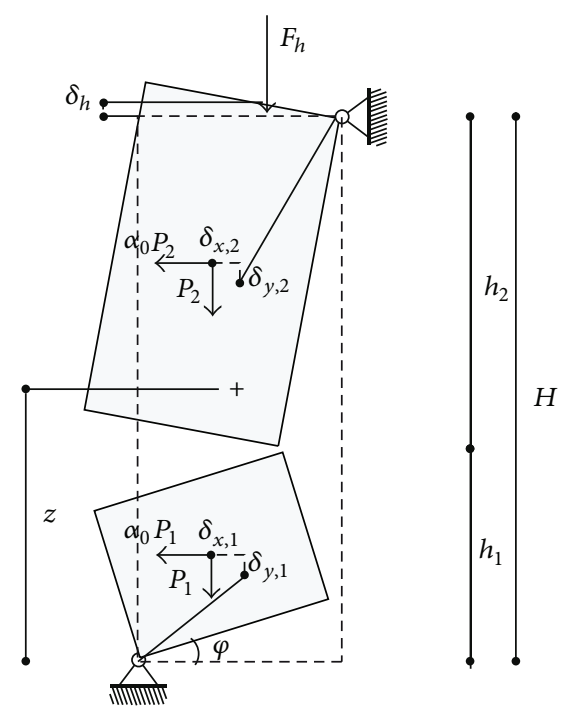

FIGURE 10: Limit analysis: representation of a generic mechanism due to the application of $F_{h}$ force and self-weights.

choice allows to better represent the nonlinear behavior of the material during the crack evolution [30-32].

The nonlinear FE analysis provides the load proportionality factor (LPF), that corresponds, at the last converged step, to the value of the load multiplier $\alpha_{0}$ that activates the failure mechanism. It is computed by means of a Riks static analysis that is constructed by imposing a horizontal set of forces generated by applying a horizontal acceleration to the whole structure, with increasing magnitude from 0 to $g$, using a function, $f(z)$, to shape the acceleration according to the Italian standards [24]. The current magnitude of the load $F_{\text {total }}$ on the structure is given by

$$
F_{\text {total }}=F_{0}+\operatorname{LPF}\left(F_{\text {ref }}-F_{0}\right) \text {, }
$$

where $F_{\text {ref }}$ is the load pattern defined in the current step and $F_{0}$ is the dead load (weight load applied in the previous step). The LPF may increase or decrease as the solution proceeds.

4.1. Mechanism 1: Out-of-Plane Mechanism of the Façade. Here, the out-of-plane mechanism of the façade, as shown in Figure 9(a), is investigated. The façade thickness is $1.1 \mathrm{~m}$, the width is $17.2 \mathrm{~m}$, and the maximum height is $H=11.7 \mathrm{~m}$. The centre of gravity of the whole façade is located at $z=6.11 \mathrm{~m}$ from the ground level.

The limit analysis yields to the collapse multiplier for the out-of-plane mechanism: $\alpha_{0}=0.09$. The corresponding seismic acceleration $\alpha_{0}^{*}=0.116 \mathrm{~g}$ does not correspond to a safe condition, since $\alpha_{\mathrm{SLU}}^{*}=0.297 \mathrm{~g}$.

Besides, subdividing the church façade according to the geometry of the openings, it is possible to identify different local mechanisms. They are not reported because they possess higher values of the collapse load multiplier. In particular, the collapse multiplier of the mechanism associated with the higher part of the façade is $\alpha_{0}=0.534$. Moreover, a detailed description of the local mechanisms of the façade is beyond the aim of the present study. For further details about this

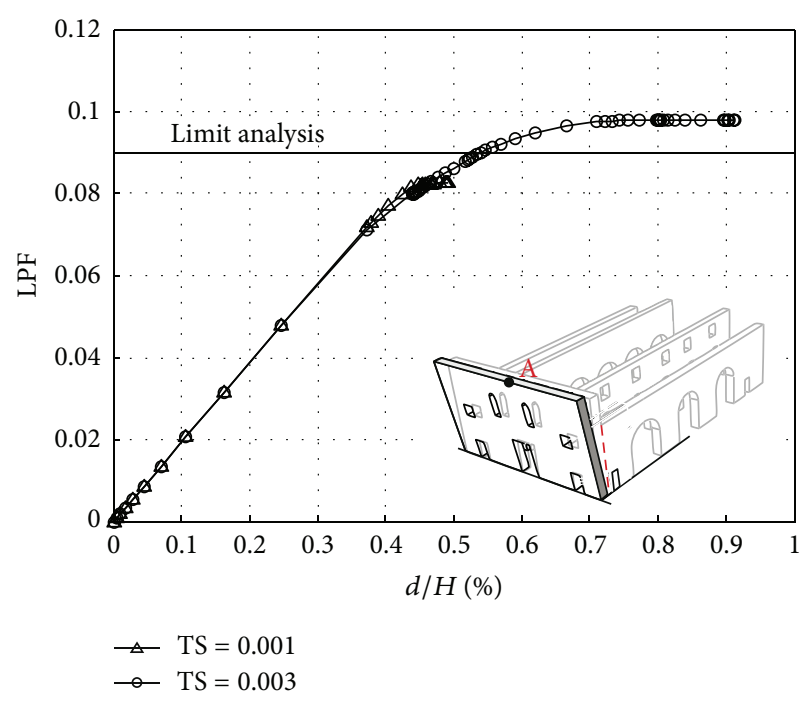

FIGURE 11: Mechanism 1: comparison between nonlinear FE analysis and limit analysis for the out-of-plane collapse of the façade.

TABLE 2: Main macroelements analyzed.

\begin{tabular}{|c|c|c|}
\hline Nr. & Description & Macroelement \\
\hline 1 & Façade & $\begin{array}{lll}1 & \mathbb{1} \\
\pi & \Pi\end{array}$ \\
\hline 2 & $\begin{array}{c}\text { Lateral nave } \\
\text { wall (C4-N3) }\end{array}$ & 101 \\
\hline 3 & $\begin{array}{c}\text { Lateral nave } \\
\text { wall }(\mathrm{N} 2-(\mathrm{C} 1 \text {, } \\
\mathrm{C} 2, \mathrm{C} 3, \mathrm{~S} 2))\end{array}$ & \\
\hline 4 & $\begin{array}{l}\text { Nave wall } \\
\text { (N3-N1) }\end{array}$ & \\
\hline 5 & $\begin{array}{c}\text { Nave wall } \\
\text { (N1-N2) }\end{array}$ & \\
\hline
\end{tabular}

aspect and about the out-of-plane behaviour of unreinforced masonry walls see [33].

Figure 11 shows the comparison between $\alpha_{0}$ and LPF obtained from the nonlinear FE analysis. The load proportionality factor LPF is plotted versus the nondimensional displacement parameter $d / H$, where $d$ is the displacement of the reference point of the mechanism, indicated with the letter A in Figure 11. The computation of LPF is carried out for values of the tension stiffening parameter TS ranging from 0 to 0.003 but, for clarity purpose, only two values of TS are plotted: TS $=0.001$ and TS $=0.003$.

4.2. Mechanism 2: Interaction between the Façade and the Peripheral Lateral Walls. Here, the failure mechanism of the 


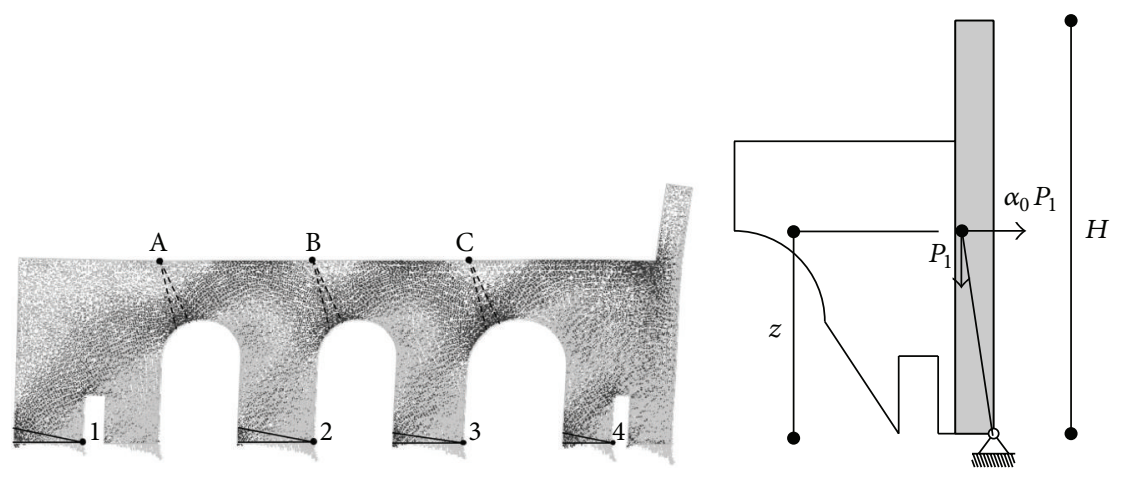

(a)

(b)

FIGURE 12: Nonlinear FE analysis: (a) principal stresses with the locations of crack openings for the lateral wall N2-(C1,C2,C3,S2). White and black colours correspond to compression and tension areas, respectively, and (b) illustration of the lateral section (see Figure 9(b)) used to compute the collapse load multiplier $(z=5.81 \mathrm{~m}$ and $H=11.7 \mathrm{~m})$.

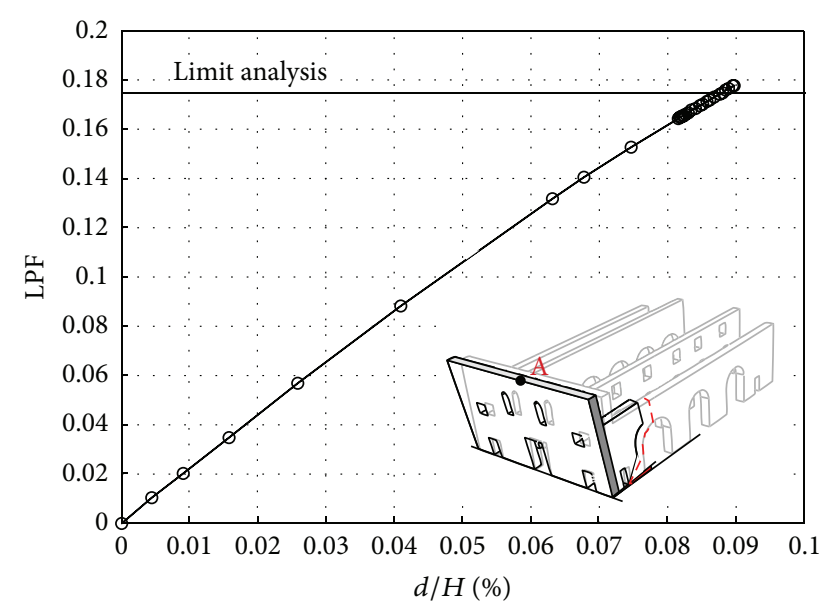

FIGURE 13: Mechanism 2: comparison between nonlinear FE analysis and limit analysis for the out-of-plane collapse of the façade considering the contribution of peripheral lateral walls.

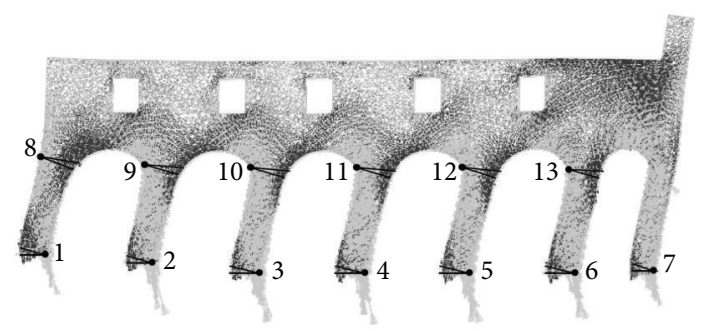

FIgURE 14: Nonlinear FE analysis: principal stresses with the locations of crack openings for the nave wall N1-N2. White and black colour corresponds to compression and tension areas, respectively.

façade with the lateral nave walls, as shown in Figure 9(b), is considered.

A preliminary in-plane $\mathrm{FE}$ analysis is performed. Figure 12(a) shows the resulting deformed configuration for the macroelement no. 3 (Table 2). The representation of the minimum (compression) and maximum (tensile) principal

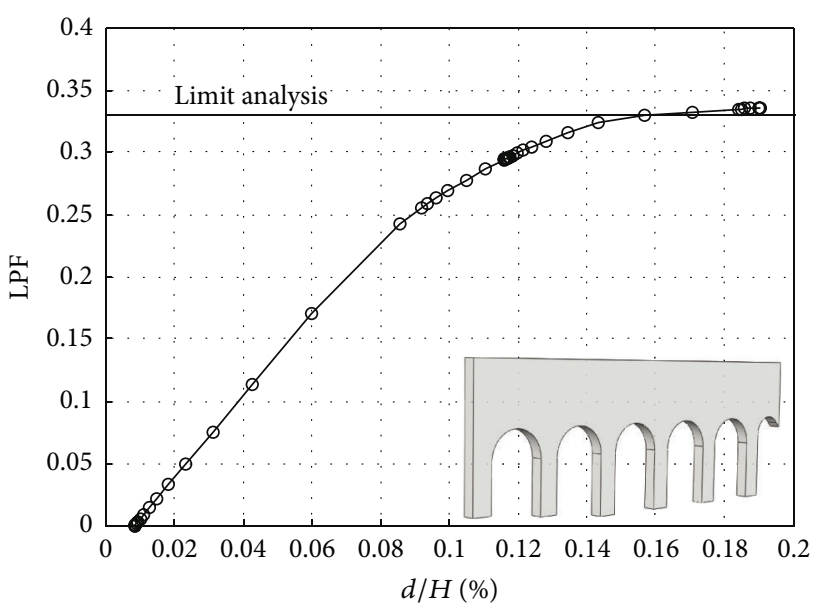

FIGURE 15: Mechanism 3: comparison between nonlinear FE analysis and limit analysis for the in-plane collapse of the nave walls.

stresses shows the critical zones, where the hinges are likely to occur: see hinges $\mathrm{A}, \mathrm{B}$, and $\mathrm{C}$ on the top of the wall and hinges 1, 2, 3, and 4 at the bottom of the wall. Based on these results, it is possible to derive the geometry of the collapse mechanism to be used in the computation of the collapse load multiplier. Moreover, the highlighted stress maps shown in Figure 12(a) are in agreement with the cracking pattern shown in Figure 4(b).

Thus, the collapse multiplier has been computed as the minimum kinematic multiplier by varying the position of the hinges in these critical zones. The geometry illustrated in Figure 12(b) has been used to compute the collapse load multiplier $\alpha_{0}$.

A 3D FE model has been constructed and a nonlinear analysis is performed by considering perfect matching between the façade and the lateral walls. This assumption provides a mechanism of the as-built condition to compare with the assumed mechanism for the limit analysis shown in Figure 12(b). 


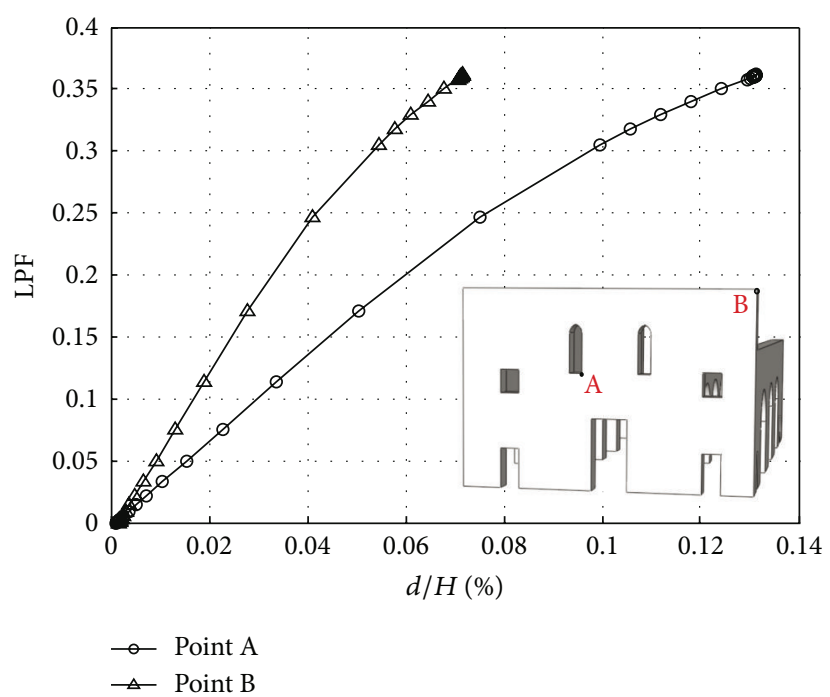

FIGURE 16: Mechanism 3: nonlinear FE analysis for the out-of-plane collapse of the façade considering the contribution of lateral and nave walls. Points A and B correspond with the location, where maximum and minimum displacements are measured, respectively.

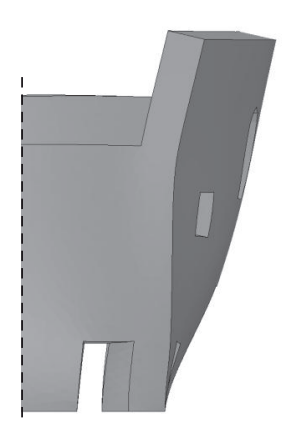

(a)

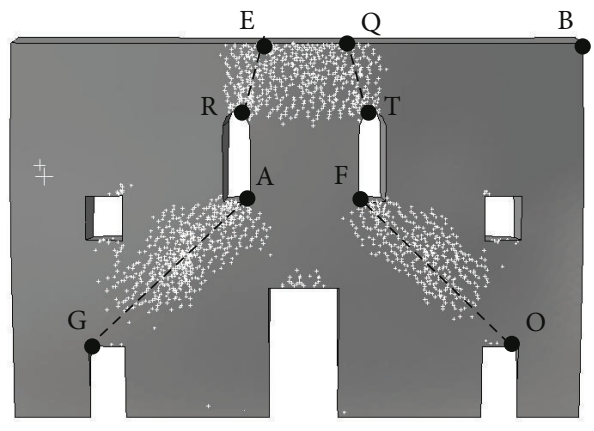

(b)

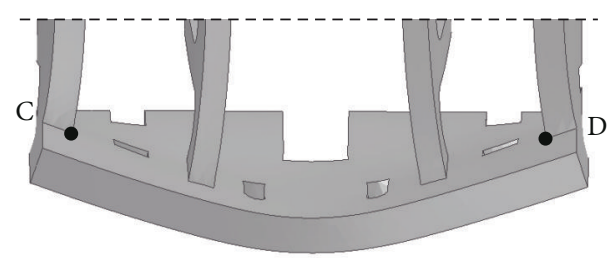

(c)

FIGURE 17: Representation of the façade mechanism: (a) lateral view of the amplified deformed shape, (b) front view with the corresponding cracking pattern, and (c) top view of the amplified deformed shape.

Figure 13 shows the results obtained using the nonlinear $\mathrm{FE}$ analysis and the limit analysis. The comparison between $\alpha_{0}=0.175$ and LPF $=0.18$ confirms that results are in good agreement. The corresponding seismic acceleration $\alpha_{0}^{*}=0.201 \mathrm{~g}$ does not correspond to a safe condition with respect to $\alpha_{\mathrm{SLU}}^{*}=0.291 \mathrm{~g}$ computed via (4). A value of 0.001 for the tension stiffening parameter TS was considered in the computations.

\subsection{Mechanism 3: Interaction between the Façade, the Periph-} eral Lateral Walls, and the Nave Walls. Here, a further study of the potential failure of the façade is carried out considering the interaction between the façade macroelement and all the longitudinal macroelements (peripheral lateral walls and nave walls); see Figure 9(c).

As for the previous case, these macroelements (nos. 4 and 5 in Table 2) are studied preliminarily by means of an inplane FE analysis. In Figure 14, the deformed configuration with the representation of the minimum (compression) and maximum (tensile) principal stresses is reported for the nave wall (N1-N2). This representation allows to identify the hinges to be used in the limit analysis.

A 3D FE model was constructed and the nonlinear FE analysis was performed by considering perfect matching between the façade and the lateral party walls. Figure 15 shows the comparison between $\alpha_{0}=0.33$ and LPF $=$ 0.34 obtained from the nonlinear FE analysis. Results are in good agreement. A value of 0.001 for the tension stiffening parameter TS was considered in the computations. Figure 16 shows the comparison between the results obtained from the nonlinear FE analysis for two control points: one in the middle of the façade, denoted as point $\mathrm{A}$, and one at the top of the façade, denoted as point $B$.

The deformed configuration of the structure is illustrated in Figure 17. The mechanism is characterized by a pronounced horizontal displacement at the center of the façade. The corresponding cracking pattern shows a severe damage localized at the top of the façade, points $\mathrm{E}$ and $\mathrm{Q}$, and the formation of two hinges along the lines F-O and A$\mathrm{G}$. This configuration is very similar to failure mechanism experienced by similar churches after earthquakes $[34,35]$. 


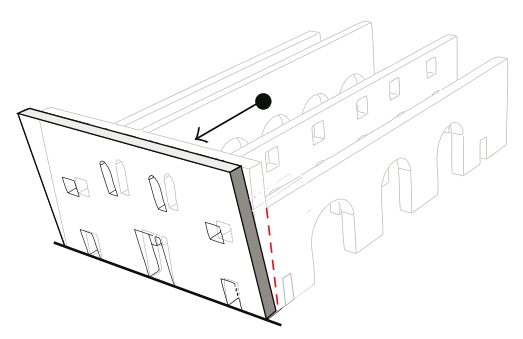

(a)

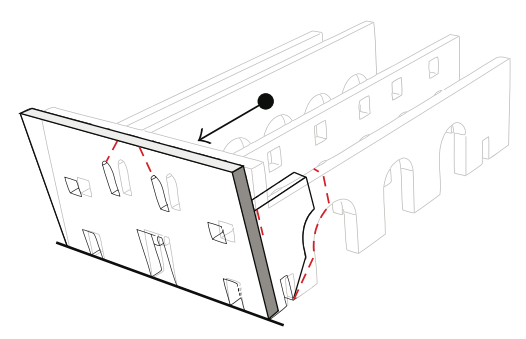

(b)

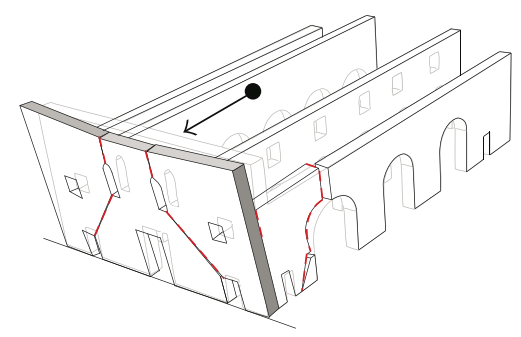

(c)

FIGURE 18: Mechanisms involving the façade macroelement. (a) Mechanism 1: no connection between the façade and the longitudinal walls; (b) mechanism 2: connection between the façade and the peripheral lateral walls; (c) mechanism 3: connection between the façade and all the transversal walls.

Figure 18 summarizes the results obtained for all the investigated mechanisms.

\section{Conclusions}

In this paper, the analysis of the seismic vulnerability of a church structure has been presented throughout the study of three collapse mechanisms of its façade. The analysis has been carried out by means of nonlinear finite element models and according to the Italian standards on monumental and historical masonry buildings. Investigations based on results obtained from limit analysis and nonlinear finite element analysis have been conducted on some macroelements with special attention to those that interact with the façade.

The obtained results showed the primary role of the interlocking effect of lateral walls on the façade behavior and the role of the conservation status of the church, its cracking pattern and its previous damage state. Analyses have allowed to obtain basic information about the structural behavior of the church under seismic loads highlighting that some of the studied mechanisms do not correspond to safe conditions. As a consequence, proper retrofitting actions can be designed.

\section{Acknowledgment}

The computing facilities were provided by the Laboratory of Computational Mechanics (LAMC), DICAM, University of Bologna.

\section{References}

[1] G. Milani, "Lesson learned after the Emilia-Romagna, Italy, 20-29 May 2012 earthquakes: a limit analysis insight on three masonry churches," Engineering Failure Analysis, 2013.

[2] G. Brandonisio, G. Lucibello, E. Mele, and A. De Luca, "Damage and performance evaluation of masonry churches in the 2009 L'Aquila earthquake," Engineering Failure Analysis, 2013.

[3] P. B. Lourenço, A. Trujillo, N. Mendes, and L. F. Ramos, "Seismic performance of the St. George of the Latins church: lessons learned from studying masonry ruins," Engineering Structures, vol. 40, pp. 501-518, 2012.

[4] C. Gentilini, A. Marzani, and M. Mazzotti, "Nondestructive characterization of tie-rods by means of dynamic testing, added masses and genetic algorithms," Journal of Sound and Vibration, vol. 332, no. 1, pp. 76-101, 2013.
[5] C. Gentilini, E. Franzoni, S. Bandini, and L. Nobile, "Effect of salt crystallisation on the shear behaviour of masonry walls: an experimental study," Construction and Building Materials, vol. 37, pp. 181-189, 2012.

[6] G. Formica, V. Sansalone, and R. Casciaro, "A mixed solution strategy for the nonlinear analysis of brick masonry walls," Computer Methods in Applied Mechanics and Engineering, vol. 191, no. 51-52, pp. 5847-5876, 2002.

[7] R. Senthivel and P. B. Lourenço, "Finite element modelling of deformation characteristics of historical stone masonry shear walls," Engineering Structures, vol. 31, no. 9, pp. 1930-1943, 2009.

[8] I. Caliò, F. Cannizzaro, M. Marletta, and B. Pantò, "A discreteelement approach for the simulation of the seismic behavior of historical buildings," in Proceedings of the 18th Italian Group of Computational Mechanics (GIMC '10), Siracusa, Italy, 2010.

[9] S. Brasile, R. Casciaro, and G. Formica, "Multilevel approach for brick masonry walls-part I: a numerical strategy for the nonlinear analysis," Computer Methods in Applied Mechanics and Engineering, vol. 196, no. 49-52, pp. 4934-4951, 2007.

[10] G. C. Manos, V. J. Soulis, and A. Diagouma, "Numerical investigation of the behaviour of the church of Agia Triada, Drakotrypa, Greece," Advances in Engineering Software, vol. 39, no. 4, pp. 284-300, 2008.

[11] M. Betti and A. Vignoli, "Assessment of seismic resistance of a basilica-type church under earthquake loading: modelling and analysis," Advances in Engineering Software, vol. 39, no. 4, pp. 258-283, 2008.

[12] G. Castellazzi, S. de Miranda, and C. Mazzotti, "Finite element modelling tuned on experimental testing for the structural health assessment of an ancient masonry arch bridge," Mathematical Problems in Engineering, vol. 2012, Article ID 495019, 18 pages, 2012.

[13] G. Castellazzi, "Cultural heritage preservation: seismic assessment of a church façade," in Proceedings of the 3rd International Conference on Urban Sustainability, Cultural Sustainability, Green Development, Green Structures and Clean Cars (USCUDAR '12), Barcellona, Spain, 2012.

[14] C. Mazzotti, S. de Miranda, G. Castellazzi, and F. Carrea, "Structural assessment of the railway masonry arch bridge crossing the Reno river in Bologna," in Proceedings of the 6th International Conference on Bridge Maintenance, Safety and Management (IABMAS '12), Cernobbio, Italy, 2012.

[15] A. De Luca, A. Giordano, and E. Mele, "A simplified procedure for assessing the seismic capacity of masonry arches," Engineering Structures, vol. 26, no. 13, pp. 1915-1929, 2004. 
[16] E. Mele, A. De Luca, and A. Giordano, "Modelling and analysis of a basilica under earthquake loading," Journal of Cultural Heritage, vol. 4, no. 4, pp. 355-367, 2003.

[17] Hibbitt Karlsson \& Sorensen Inc., Abaqus Theory Manual, 1998.

[18] H. R. Lotfi and P. B. Shing, "An appraisal of smeared crack models for masonry shear wall analysis," Computers \& Structures, vol. 41, no. 3, pp. 413-425, 1991.

[19] M. Dhanasekar and W. Haider, "Explicit finite element analysis of lightly reinforced masonry shear walls," Computers \& Structures, vol. 86, no. 1-2, pp. 15-26, 2008.

[20] M. Brigante, A. Cozzo, G. Frunzio, and M. Fulgione, "Valutazione sperimentale delle tensioni in mu3 ratura di tufo giallo napoletano," in Atti del II Convegno, Salerno, Italy, September 2003.

[21] M. Betti and A. Vignoli, "Modelling and analysis of a Romanesque church under earthquake loading: assessment of seismic resistance," Engineering Structures, vol. 30, no. 2, pp. 352-367, 2008.

[22] J. Heyman, "The safety of masonry arches," International Journal of Mechanical Sciences, vol. 11, no. 4, pp. 363-385, 1969.

[23] P. Block, T. Ciblac, and J. Ochsendorf, "Real-time limit analysis of vaulted masonry buildings," Computers \& Structures, vol. 84, no. 29-30, pp. 1841-1852, 2006.

[24] S.O. n. 30. G.U. n. 29, 4 Febbraio 2008, “D.M. del Ministero delle Infrastrutture e dei Trasporti 14 Gennaio 2008, Nuove Norme Tecniche per le Costruzioni," Italy, 2008.

[25] Min. II.TT.C.S.L.P., "Istruzioni per l'applicazione delle "Nuove norme tecniche per le costruzioni" di cui al decreto ministeriale 14 gennaio 2008. Circolare del 2/2/2009, n. 617 del Ministero delle Infrastrutture e dei Trasporti approvata dal Consiglio Superiore dei Lavori Pubblici, Suppl. ord. n. 27 alla G.U. del 26/02/2009 n. 47," 2008.

[26] S. V. Chaudhari and M. A. Chakrabarti, "Modeling of concrete for nonlinear analysis using finite element code ABAQUS," International Journal of Computer Applications, vol. 44, no. 7, pp. 14-18, 2012.

[27] C. Gentilini, G. Gottardi, L. Govoni, A. Mentani, and F. Ubertini, "Design of falling rock protection barriers using numerical models," Engineering Structures, vol. 50, pp. 96-106, 2013.

[28] M. A. Ramalho, A. Taliercio, A. Anzani, L. Binda, and E. Papa, "A numerical model for the description of the nonlinear behaviour of multi-leaf masonry walls," Advances in Engineering Software, vol. 39, no. 4, pp. 249-257, 2008.

[29] A. Giordano, E. Mele, and A. De Luca, "Modelling of historical masonry structures: comparison of different approaches through a case study," Engineering Structures, vol. 24, no. 8, pp. 1057-1069, 2002.

[30] L. Berto, A. Saetta, R. Scotta, and R. Vitaliani, "Failure mechanism of masonry prism loaded in axial compression: computational aspects," Materials and Structures, vol. 38, no. 276, pp. 249-256, 2005.

[31] J. M. Adam, A. Brencich, T. G. Hughes, and T. Jefferson, "Micromodelling of eccentrically loaded brickwork: study of masonry wallettes," Engineering Structures, vol. 32, no. 5, pp. 1244-1251, 2010.

[32] P. B. Lourenço and J. Pina-Henriques, "Validation of analytical and continuum numerical methods for estimating the compressive strength of masonry," Computers \& Structures, vol. 84, no. 29-30, pp. 1977-1989, 2006.

[33] H. Derakhshan, M. Griffith, and J. Ingham, "Out-of-plane behavior of one-way spanning unreinforced masonry walls,"
Journal of Engineering Mechanics, vol. 139, no. 4, pp. 409-417, 2013.

[34] G. Cifani, A. Lemme, and S. Podesta, "Beni monumentali e terremoto," DEI srl, Tipografia del Genio Civile, Roma, Italy, 2005.

[35] M. Como and A. Grimaldi, "An unilateral model for the limit analysis of masonry walls," in Unilateral Problems in Structural Analysis, Springer, London, UK, 4th edition, 1985. 

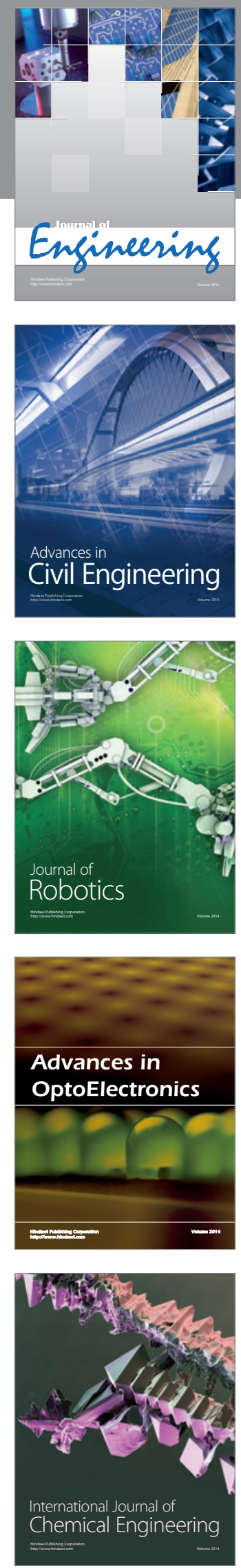

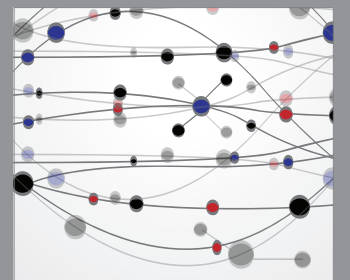

The Scientific World Journal
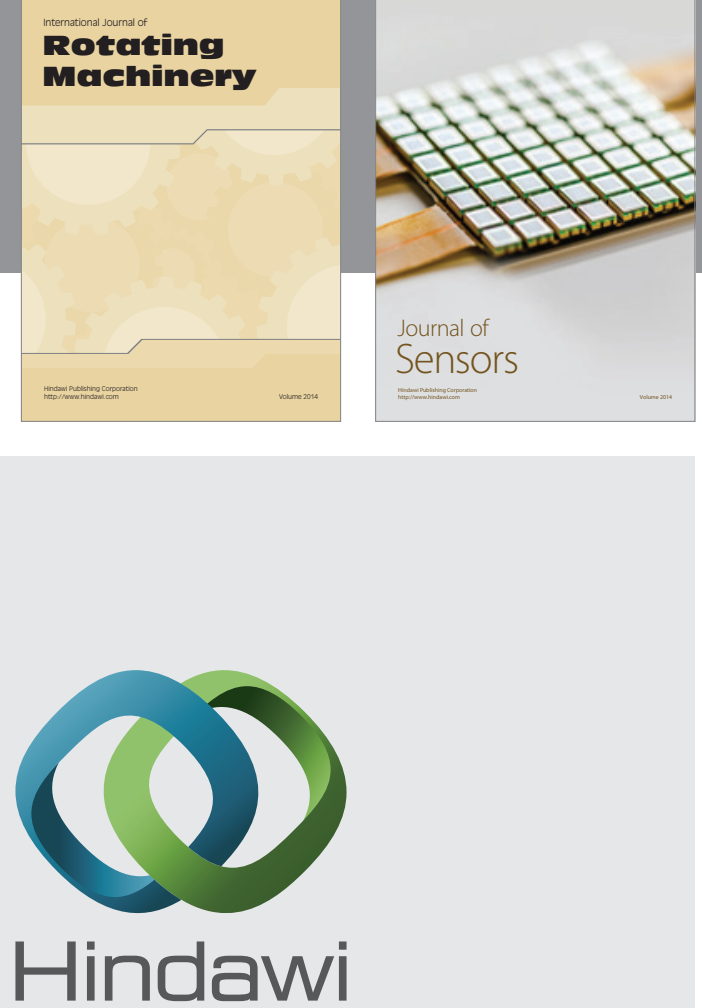

Submit your manuscripts at http://www.hindawi.com
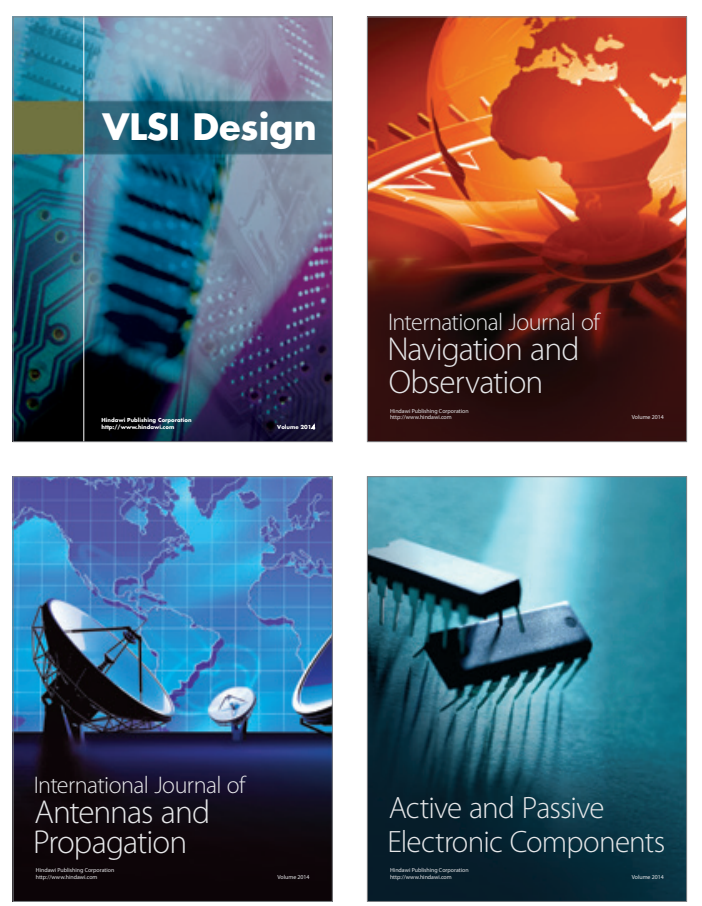
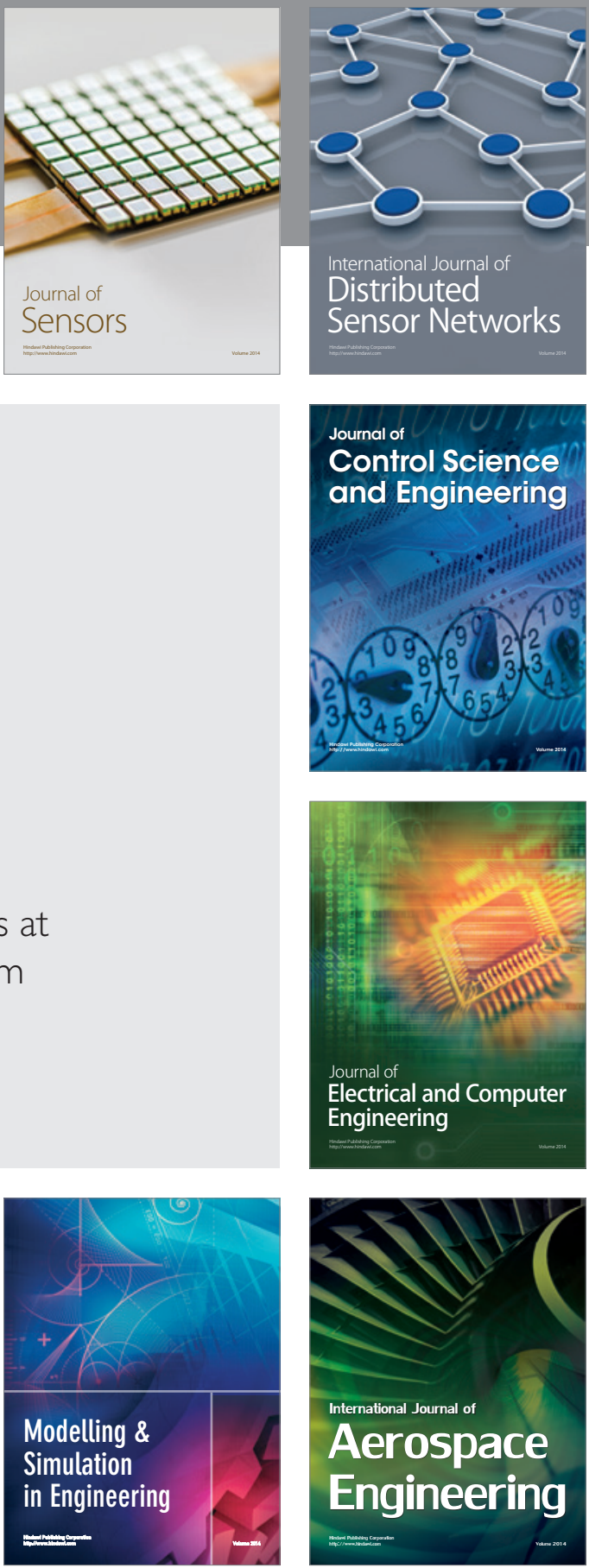

Journal of

Control Science

and Engineering
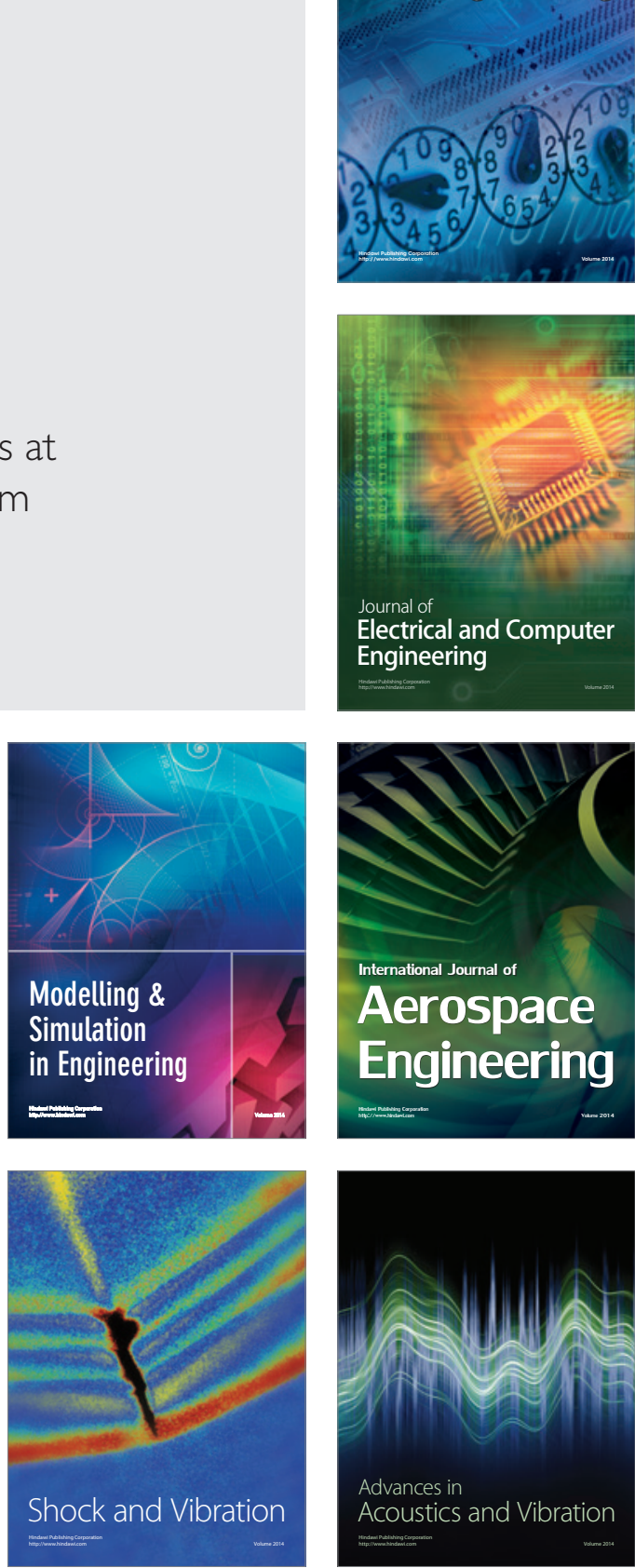